\title{
Finding the Right Amount of Openness, Compromise, and Huidu, and Properly Balancing Expansion and Control
}

According to Huawei's management philosophy, a company is an open system filled with contradictions. All contradictions co-exist, interacting with, standing against, and changing into each other. This upward reinforcing spiral creates the momentum that propels the company forward. Properly handling contradictions requires the right amount of openness, compromise, and buidu, and is a key part of the art of leadership.

Lao Tzu, the ancient Chinese philosopher and the founder of Taoism, said, "If you want to fold something, you must first unfold it. If you want to weaken something, you must first make it strong. If you want to let something decay, you must first let it prosper. If you want to have something, you need to first set it free. This is the plain truth." He further states, "The guiding principle behind Taoism is that everything can be its own opposite. Taoism advocates adaptation rather than change." This philosophy of opposites complementing each other is a dialectical approach that can be used to observe things and promote their development by leveraging contradictions.

Control and expansion are at odds with each other. The need to exert control is a natural result of expansion as it can cause risks. The purpose of control, however, is to expand more effectively.

The most notable aspect of Huawei's management philosophy is the idea of "creating order out of chaos and creating chaos out of order", as proposed by Huawei CEO Ren Zhengfei. IBM's consultants said that Huawei “didn't have time to do things right the first time, but did have

(C) The Author(s) 2019

W. Huang, Built on Value, https://doi.org/10.1007/978-981-13-7507-1_6 
time to do the same thing over and over again" with its own self-developed management system. Under the guidance of consultants from IBM and other renowned consulting firms, Huawei has successfully implemented five major process transformation programs and established an advanced, modern management system. The five transformation programs are Integrated Product Development (IPD), Integrated Supply Chain (ISC), Integrated Financial Services (IFS), Customer Relationship Management (CRM), and IT Strategy \& Planning (IT S\&P). These transformations have dramatically changed the company's processes, improved operating efficiency and business performance, and have allowed the company to "create order out of chaos". However, Ren Zhengfei soon after proposed another concept, which was to "create chaos out of order, disrupt balance, and continue to expand". This can be seen as the largest defining feature of Huawei's management philosophy.

This chapter elaborates on six contradictions that arise from expansion and control. Other contradictions are integrated into other chapters of this book.

\subsection{Opportunity-Driven Versus Resource-Driven}

\subsubsection{More Emphasis on Opportunity-Driven Resource Allocation}

Large companies usually invest about $10 \%$ of their sales in R\&D to create opportunities. China lags far behind in this regard. We identify opportunities only after they emerge and seize them to achieve success. This is what happens at Huawei. However, the world's leading companies create opportunities through R\&D to shape consumption. They quickly gather up all profits within a short window of opportunity and then reinvest the profits to create even greater opportunities. That is why these companies develop faster than we do. (Ren Zhengfei: What Can We Learn from the American People?, Improvement Issue No. 63, 1998)

Opportunities are the driving force behind company growth. (Ren Zhengfei: What Can We Learn from the American People?, Improvement Issue No. 63, 1998)

Western companies drive company development with resources. At Huawei, we emphasize that opportunities drive company development. (Ren Zhengfei: Timely, Accurate, High Quality, and Low Cost Delivery Calls for Professional Process-compliant CFOs-Minutes of a Meeting with 
Trainees of the CFO Session of the Reserve Pool, Huawei Executive Office Speech No. [2009] 021)

We must leverage our core resources to identify new targets and opportunities, and then turn those opportunities into business results. Advanced equipment and high-quality resources in our back offices should be utilized promptly once field offices identify targets and opportunities. In other words, back offices shouldn't try to command operations just because they own resources; instead, they should support field operations. Who should call for support? Those closest to customers. They are the people who should make decisions. (Ren Zhengfei: Who Calls for Artillery and How Do We Provide Timely Artillery Support?-Speech at the Awards Ceremony of Sales \& Services, Huawei Executive Office Speech No. [2009] 001)

I think cost and quality are the product and soul of the industrial economy. We are no longer in the industrial age, but we still haven't changed our mindset. Value creation doesn't completely rely on cutting costs and improving quality. We must maintain a strategic focus and leverage our resources to develop features that can help us hone our competitive edge. (Ren Zhengfei: Working Together Towards the Same Goal, Concentrating Advantageous Resources on Our Core Business, and Having the Courage to Seek Greater Opportunities and Further Widen the Gap-Minutes of the Work Report on the Wireless Business, Huawei Executive Office Speech No. [2011] 039)

We must seize opportunities created by industry transformation and dare to increase investment to seize strategic opportunities. We need to narrow our strategic focus, seize the strategic high ground, and ultimately achieve sustainable and profitable growth, thus laying the foundation for survival and long-term development. (Ren Zhengfei: Guidelines on the Analysis of the Business Environment and Key Business Strategies, Corp. Doc. No. [2012] 081)

Humanity is at a turning point. In the next two to three decades, we will enter an intelligent world, where we will see an information explosion. This will present us with huge opportunities, but without a direction or strength, we will not be able to create value. Without making correct assumptions, there will be no correct direction. Without a correct direction, there will be no correct ideas. Without correct ideas, there will be no correct theories. Without correct theories, there will be no correct strategies. (Ren Zhengfei: Remarks at Meetings with Huawei Fellows, Huawei Executive Office Speech No. [2016] 069) 


\subsubsection{Channeling High-Quality Resources to Valued Customers, Valued Countries, and Mainstream Products}

We need to be clear about who our primary strategic partners are in each region and what their relationships with us are. We will then serve them with our best resources, such as our best service managers and sales managers. (Ren Zhengfei: Eight Points Made After Receiving the "2008 Business Plan and Budget" Report at the EMT ST Meeting on January 31, EMT Meeting Minutes No. [2008] 009)

As we build strategic partnerships with customers, we should not confine ourselves to just sales and delivery. We should open our minds and think carefully about what value we bring to customers. We need to make customers fully aware of what we do as their strategic partner during the joint development process and how our strategies align and how much extra value we can create. (Source: Guidelines on Sales Priorities, EMT Meeting Minutes No. [2008] 014)

The most crucial factor in achieving our sustainable growth is establishing a favorable presence in three areas: valued customers, valued countries, and mainstream products. Therefore, product lines and regions must reasonably allocate human resources; priority should be given to these three areas, rather than to products and regions with weak growth momentum. We must expand our competitive presence in these three areas in order to support our sustainable growth. (Source: Issues and Principles That Require Attention During Near-term HR Management, EMT Resolution No. [2009] 002)

We must use practical principles and methods to prioritize markets. We should adopt Tian Ji's ${ }^{1}$ horse racing strategy and prioritize markets based on our strategic advantages and previously secured opportunities. We need to allocate resources based on feasibility. We must avoid prioritizing markets based on our supposed share in markets around the world. This doesn't mean we will give up markets that are not on our priority list. We still need to pursue potential opportunities. (Ren Zhengfei: Minutes of the

${ }^{1}$ Tian Ji (田忌; c. 340 CE) was a military general of the Qi state during the early Chinese Warring States period (fourth century BC). At a horse-racing event hosted by the king, an acquaintance recommended Tian Ji follow a specific strategy to win. Tian used his inferior horse to race with the king's best horse, his average horse to race with the king's inferior horse, and his best horse to race with the king's average horse, winning two out of three races. 
Report on the Company's 2010 Business Plans and Budgets, EMT Meeting Minutes No. [2010] 006)

We should boldly change our business models, shut down operations in unprofitable countries, and walk away from certain customers. Fewer countries mean lower costs, so we can focus on delivering good services. Why do we have to cover 170 different countries and regions? If we are to ensure a reasonable level of profits in software, then we need to shift from "meeting the needs of every customer" to "serving valued customers". We also need to reorganize the geographic layout of our software organizations. Not every representative office needs a software department; only large carriers and large representative offices should have one. We do not have to let ourselves be dragged around by the nose by small carriers. Software sales departments should be relatively independent. If you are not independent, then the core business will pin you down and treat you like a free giveaway used to secure customers' contracts. So you have to be bold enough to end business with some customers, and just serve valued ones. (Ren Zhengfei: Focusing on the Core Business and Seizing Strategic Opportunities-Speech at the Product Investment Strategy Review Meeting, Huawei Executive Office Speech No. [2015] 123)

Don't give up any country. Every market is critical to Huawei. At the same time, we must make strategic choices and focus on valued customers. If you give up one small country, you will then give up a second one, a third one, and eventually all of them. You will be pushed steadily back into China. If you continue to give up Tibet, Yunnan, and Guizhou, then Xinjiang, and Qinghai, then only Beijing and Shanghai will be left for us. These two markets are the most profitable, but can we retain them? Once we are surrounded, we will be doomed. To survive, we must value each and every market. Every region is important, but we should select our customers carefully. Not everyone who has demand will become our customer. If they don't pay, how can they be called a customer? Only those who pay for what they demand and allow us to make profits are our customers. Those who pay more than others are valued customers. We need to change our understanding of who our customers should be. It's a big world; we cannot meet all customer needs. (Ren Zhengfei: Speech at a Meeting with Employees of the Central Asia \& Caucasia Region, Huawei Executive Office Speech No. [2016] 063) 


\subsubsection{Managing Investment Portfolios and the Pace of Investment Based on Corporate Strategy, Investment Capacity, and Business Opportunities}

We need to strengthen product and business portfolio management, steadily promote diversification in certain domains, and explore more flexible ways to duplicate our advantages in the marketplace, technology, and management, including through capital investment. This will shorten the time needed to enter new domains and help us achieve greater synergy. (Ren Zhengfei: Work Report to the Board of Directors on the Completion of the 2003 Business and Budget Goals, 2004)

For a single product line, optical transmission, for example, we can further lower gross profit margins for low-end products in order to outperform our strategic competitors. At the same time, we need to continuously improve our profitability in high-end products where our competitors lack a competitive edge. We must not ignore low-end products as we strive to succeed in high-end products; otherwise, we will be handing opportunities to our strategic competitors. (Source: Guidelines on Sales Priorities, EMT Meeting Minutes No. [2008] 014)

We need to separate mature and emerging industries during our appraisals. The company can strategically subsidize newly emerging industries during their first three to five years, and those industries can repay the company later on after they have grown. We shouldn't use a mature industry to subsidize an immature one. This support should be provided by the company, not by a product line. (Ren Zhengfei: Speech at the EMT ST Meeting on April 29, 2010)

How exactly should we assess opportunities and decide which to seize? What should we do and what should we not do? Should we do things for strategic purposes or just make normal deals? By strategic purposes, I mean we allow short-term losses; by normal deals, I mean we should shut a business down if it loses money. (Source: Minutes of the Report on the 2012 Group Budget Review, EMT Meeting Minutes No. [2012] 012)

Our corporate strategy should focus on our core business of massive data traffic. First, we must boldly seize the strategic high ground with our high-end products and must not sell them too cheaply. We can then duplicate our advantages in high-end products among mid-range and low-end products. Second, we must ensure high quality and low costs for our midrange and low-end products. We must increase our scale in these two market segments. Our mid-range and low-end products must be 
maintenance-free throughout their lifecycle. (Ren Zhengfei: Speech at a Meeting with Elite Teams at the Training Camp on July 23, 2013, Huawei Executive Office Speech No. [2013] 174)

We must keep our pace of market investment under control and have the courage to give up some regions where we are not achieving the value we expected. You need to focus on regions with potential, and fully share resources with local account departments and representative offices to improve business results. For actual market investment strategies, you can learn from how we handled the carrier market in our early years, assigning a small team to a new market at the beginning and then expanding the team after the market had grown. (Source: Minutes of the Report on the Progress of the Enterprise BG's Focus Strategy, EMT Meeting Minutes No. [2012] 018)

As we compete for the high-end market, we must not lose our grip on the low-end. Today we are adopting a "needle-tip" strategy and maintaining a tight focus as we move forward. What I'm worried about is that we may dive head first into a new target market, but leave our backs exposed. If we leave the low-end market open to others, we may just be nurturing potential competitors. Ultimately, our high-end market will be affected as well. Huawei has drawn energy from the low-end market to enter the high-end. Why wouldn't other companies follow our example? (Ren Zhengfei: Innovating to Create Global Value-Speech at the Corporate Strategy Retreat, Huawei Executive Office Speech No. [2015] 006)

Our low-end products must be standardized, streamlined, and maintenance-free during their entire lifecycle. We are not walking the path of low price and low quality. That would undercut our ability to make strategic moves. In terms of technology and service models, we must become highly competitive through mass production. If customers want more functionality, they can buy our high-end products. This is the "milea-minute weed"2 theory, and we now have this advantage. (Ren Zhengfei: Innovating to Create Global Value-Speech at the Corporate Strategy Retreat, Huawei Executive Office Speech No. [2015] 006)

We are still engineers with business acumen. In fact, our innovation is still limited to engineering; it does not have much to do with technological theories. We have not been sufficiently engaged in technological innovation, but we already have access to scientists and professors from

\footnotetext{
2 "Mile-a-minute weed" is an extremely vigorous plant that can survive and grow quickly even in harsh conditions.
} 
technological domains. This is one direction in which we're heading, and so we should begin to develop a culture of scientists. Just as you have said, we haven't reached this level yet. And I hope we will place emphasis on this in the future. (Ren Zhengfei: Remarks at Meetings with Huawei Fellows, Huawei Executive Office Speech No. [2016] 069)

\subsubsection{Keeping the Costs of Resources in Mind and Acquiring Resources to Achieve Growth Goals}

We must introduce the concept of cost management to our work. We need to manage cost and forbid extravagance and waste. We can't do this simply by looking at money or performance indicators. We need to analyze many things. For example, what has caused an increase in cost? How much of this increase is truly necessary? How much have we invested in R\&D? How many opportunities has this investment created? How much of our investment has failed? What percentage is it of our total R\&D investment? Is this percentage reasonable? (Ren Zhengfei: Speech at a Meeting with Commodity Experts Groups, 2000)

We must improve the quality of our operations and drive sustainable and profitable growth. We must better incorporate the company's strategic pursuits into our business goals and closed-loop performance appraisals. We need to improve the way we manage risks, maintain robust, standardized operations, and remain calm in the face of uncertainties in the global economy. We should boldly invest in strategic opportunities to pursue growth. However, the resources we acquire must be used to achieve our committed goals for business growth. We must manage planning, budgeting, and accounting in a closed loop, and directly link business results to the performance ratings and incentives of those responsible for decision making and execution. (Ren Zhengfei: Guidelines on the Analysis of the Business Environment and Key Business Strategies, Corp. Doc. No. [2012] 081)

Field teams will have the authority to directly call for support within their scope of authorization. This means that during project management, authority will be delegated according to the authorization documentation provided by IBM consultants that cover contract terms, contract signing, and pricing, as well as based on gross profit margins and cash flows. Within their scope of authorization, field teams can directly command operations. But matters beyond the scope of authorization need to be approved. Of course, calling for support incurs costs, which need to be borne by those 
who have called for the support. They also need to be held accountable for the decisions they make. (Ren Zhengfei: Who Calls for Artillery and How Do We Provide Timely Artillery Support?-Speech at the Awards Ceremony of Sales \& Services, Huawei Executive Office Speech No. [2009] 001)

Additional resources we invest need to be ultimately reflected in ambitious business goals. We need to assess whether resource investment is reasonable using clear and measurable business performance indicators. (Source: Minutes of the Report on Business Forecasts and Compensation Package Baseline Calculations for the Next Three Years, EMT Meeting Minutes No. [2011] 002)

Our Human Resource Management Dept needs to develop policies that specify the relationship between budgets and value distribution. Some business units are wasting too much money, and are exceeding budgets before completing their plans. We have to deduct some of their bonuses. In contrast, some other business units have saved money but didn't miss any strategic opportunities, so their current business performance is also good. Should we give back some of the money they saved? This should be reflected in our HR policies. Closed-loop management will absolutely affect value distribution. Both budgeting and accounting should be managed in a closed loop. If you use the budget we give you to hire more people, acquire more resources, and invest them in strategy execution, we will see what business results you have achieved during accounting. The value you share will be based on the business results you have achieved. If we establish a link between budgets, accounting, and headcount, constraints will be automatically in place. (Ren Zhengfei: Using Budgeting and Accounting to Drive Sustainable and Profitable Growth in Huawei's Core Business-Speech at the Retreat on the Positioning and Responsibilities of the Finance Committee, 2012)

\subsubsection{Guiding Resource Allocation with Differentiated Value Assessments}

Our market investment budgets should continue to be based on relative numbers. We can gradually align budgets with business targets based on the historical patterns of change in our expense/revenue ratios so that increases in business expenses, especially customer-facing expenses, align with sales growth. We need to use different expense/revenue ratios for emerging and mature markets. In terms of $R \& D$ investment, we must not simply calculate decreases in $\mathrm{R} \& \mathrm{D}$ expense/revenue ratios. We need to set 
different expense/revenue ratio targets for different product lines. It is okay for the expense/revenue ratios of mature product lines to decrease by 1 percentage point. For immature product lines though, whether we need to decrease the ratios, or how much we need to decrease them, has to be discussed at length. Don't use a single percentage for all product lines when decreasing R\&D expense/revenue ratios. You just need to calculate how much the overall R\&D expense/revenue ratio is lowered based on data from each product line. You shouldn't be overly focused on performance indicators. (Ren Zhengfei: Comments at the Meeting Regarding the Planning and Budgeting Work for 2005, 2004)

We need to channel high-quality resources to markets that contribute more value to our company. Identifying and managing regional markets based on their differences in terms of value and development is important. (Source: Minutes of the Report on Differentiated Management Plans for Regional Markets, EMT Meeting Minutes No. [2008] 039)

The Finance Committee (FC) is the company's overall enterprise value integrator. The FC operates under the Board of Directors and uses budgeting and accounting to exercise macro control over business operations, investment activities, and enterprise risks. Ultimately, this helps strike a dynamic balance between opportunities and resources, the two drivers that facilitate sustainable and profitable growth. The FC should focus on the company's key strategy while conducting macro control, decision making, and oversight activities. Through management processes like resource allocation, budgeting, and accounting, the FC guides the company to improve efficiency and business performance, and facilitate sustainable and profitable development for the company. (Source: Positioning and Responsibilities of the Finance Committee Under the Board of Directors [Provisional], Board of Directors Doc. No. [2012] 002)

We will allocate resources from a value management perspective. The FC is responsible for the company's overall macro controls. It uses budgeting and targeted accounting to generate opportunities and control our pace of development. The FC also oversees the pace, direction, and structure of resource investment, channels more resources into highvalue domains, and focuses on business results in low-value domains. The FC's ultimate goal is to meet the entire company's profit requirements. (Guo Ping: Effectively Managing Corporate Value to Pursue Sustainable and Profitable Growth, Huawei Executive Office Speech No. [2012] 005) 


\subsection{Growth Versus Profits}

\subsubsection{Focusing on Long-Term Strategic Development to Turn Today's Cash into Tomorrow's Profits}

The overall objective of our company is to increase sales and profits. We must increase R\&D investment. If the investment turns out to be worthwhile, it will bring us more opportunities, and we must cherish these opportunities. We must also increase investment in marketing and sales, as this can help us obtain new opportunities. We must seize these opportunities, as the value they bring will be higher than their costs. When there are conflicts between opportunities and costs in the company, which is more important? Our answer is opportunities. I always believe that, in the tech industry, the value opportunities bring is higher than their costs. As long as opportunities bring value, an increase in costs is acceptable. (Ren Zhengfei: Minutes of a Work Report on Annual Taxes and Budgets, 2001)

Huawei has been built on waste. Over the years, Huawei has wasted a lot of money, but the lessons we have learned in doing so will pay off eventually. Integrating all of our processes will unleash great energy and we will finally have a highly effective team. Once that happens, we will no longer rely on huge numbers of people to succeed, and the compensation of our remaining people will increase accordingly. (Ren Zhengfei: Speech and Comments at the Strategy Retreat of the Business Process of IT Management Department, Huawei Executive Office Speech No. [2012] 026)

We now need to make heavy, focused investment in our strategic areas. Once we seize the strategic high ground, we can sell our products at higher prices and generate more profits, which can then be invested in advanced research. (Ren Zhengfei: Comments to Staff of the Enterprise BG, Huawei Executive Office Speech No. [2014] 006)

\subsubsection{Focusing on Both Opportunity-Driven Scaled Growth and Profit-Driven Sustainable Growth}

We have already assigned a weight to positive profits, positive cash flow, and per-capita efficiency improvements during performance appraisals. In fact, we have made a big shift in the direction of our appraisals. This shift though, has occurred very slowly. I am not saying that you no longer need to focus on sales. Instead, I am asking you to focus hard on these three indicators. We have a team of more than 80,000 employees. Such a large 
team losing momentum would be disastrous. So we must continue to forge ahead. This change has already begun and will not progress too quickly. As long as we move in the right direction, we will achieve the desired results. (Ren Zhengfei: Speech at a Meeting with the IFS Project Team and Staff from Finance, Huawei Executive Office Speech No. [2009] 004)

Investment in and subsidies for emerging growth opportunities may increase the company's overall expenses, but this is positive growth. We need to take a positive attitude toward this. The company doesn't pursue excessively high profits; rather, we strive to turn excessively high profits into momentum for future growth. (Ren Zhengfei: Minutes of the Report on the Company's 2010 Business Plans and Budgets, EMT Meeting Minutes No. [2010] 006)

You need to figure out what strategies you should adopt. I will not tell you whether you should increase scale or profits first. This must be your decision. If you can't make a decision on this, you, as country CEOs, are not worth the compensation the company pays you. (Ren Zhengfei: Be Bold at Work, Be a Humble Person, and Follow the Patterns of Consumer Products in the Pursuit of Maximum Growth and Success-Speech at a Meeting with the Key Employees of the Consumer BG, Huawei Executive Office Speech No. [2011] 014)

Many of our offices in small countries have made good profits, and so we need to consolidate our position in these countries. We need to be selective about what we do and what we don't do in small countries. Our goal is to earn profits. A portion of our profits can be given back to regions and representative offices so that they can improve the quality of services they provide to customers. (Ren Zhengfei: Minutes of the Report on the 809 Strategic Guidelines, EMT Meeting Minutes No. [2012] 016)

We need to maintain a steady profit flow and a robust financial position. This is necessary for Huawei to continuously invest in the future and for the industry to maintain a reasonable level of profits. This is also conducive to building a long-term and stable environment for market competition. (Ren Zhengfei: Speech and Comments at the Carrier Network BG's Strategy Retreat in Huizhou, Huawei Executive Office Speech No. [2012] 010)

Our growth must be sustainable and profitable. Our warehouses should hold food instead of dust and mice. The management teams and heads of departments that are talking about various types of innovations or models should rein in their impulses, carefully analyze the costs and benefits of 
their projects, and align their personal financial interests with their commitments. They need to share both benefits and losses. (Guo Ping: Effectively Managing Corporate Value to Pursue Sustainable and Profitable Growth, Huawei Executive Office Speech No. [2012] 005)

Our employees in the Consumer and Enterprise BGs must not rush to catch up with Apple or Cisco. No matter how high the Himalayas are, there is still only a single summit. It is very cold at the top, and you can't stay there for 20 years. When you collapse, where will you deploy your extra people? I can't fix that for you. When I say not to rush to catch up, I mean hold back from scaling up too quickly. We should still aim to increase profits. Currently neither the Consumer BG nor the Enterprise BG is convinced. So you adopt a betting mindset, and one "general" will be made at the sacrifice of numerous "foot soldiers". I think you need to adopt a mindset of long-term survival, be practical, and gradually improve profitability. (Ren Zhengfei: Speechat the EMTSTMeeting on March29, 2013)

We need to shift our operational focus from the blind pursuit of scale to long-term, sustainable growth - profitability, efficiency, and quality. Product lines and business units in non-strategic domains need to set high profit targets. This is to inhibit their expansion and avoid spreading our human resources too thin. (Ren Zhengfei: Building a Highly Competitive Team-Speech at the Q3 Regional Presidents' Meeting, Huawei Executive Office Speech No. [2013] 093)

\subsubsection{Company Operations: A Dissipative Structure}

What is a dissipative structure? If you exercise every day, you are in a dissipative state. Why? Because you dissipate energy, turning it into muscle and increasing blood flow. If you dissipate all latent energy, you can avoid obesity and diabetes, and instead remain fit and attractive. This is the simplest example of dissipative structure that I can think of. Then why do we need this dissipative structure? If everyone says that they are loyal to the company, that is because the company pays them too much and such loyalty may not last long. Therefore, we need to dissipate this love for the company and instead rely on dedicated employees and processes to make the company stronger. Dedicated employees work hard first before they get paid. Their loyalty is different from that of those who get paid well first. Knowing the difference is a kind of progress for us. We need to dissipate our potential energy to create new momentum. (Ren Zhengfei: Success Is Not a Reliable Guide to Future Development-Speech at the 
Huawei Market Conference on January 17, 2011, Huawei Executive Office Speech No. [2011] 004)

We have been embracing changes, alternating between stability and instability and between balance and imbalance. The purpose of this is to maintain the company's vitality. If you eat too much beef and don't exercise, you may become obese; but if you eat a lot of beef and exercise hard enough, you could become the next Liu Xiang. ${ }^{3}$ In both cases you are eating beef, but you end up in completely different places by the end; it all depends on whether you dissipate energy or not. (Ren Zhengfei: Success Is Not a Reliable Guide to Future Development-Speech at the Huawei Market Conference on January 17, 2011, Huawei Executive Office Speech No. [2011] 004)

During our first 20 years, we focused more on internal balance to create synergies and be more effective. Over the next 20 years, we hope to disrupt balance to generate greater energy and achieve greater success. (Ren Zhengfei: Speech at the Meeting of the New Board of Directors and the New Supervisory Board, Huawei Executive Office Speech No. [2011] 001)

Huawei is doing quite well in its current stage. We should increase investment to dissipate our current advantages and create new ones. The entirety of society is going through a rough patch, and the global economy might be about to enter a cyclical downturn. Our numbers show that our growth is slowing, but we're still in relatively good shape compared with other companies. We must not hesitate to invest in our future. It is a lack of leaders, generals, and long-term strategies that has made us hesitate in making investments. (Ren Zhengfei: Speech at the Meeting with Staff from the 2012 Laboratories, Huawei Executive Office Speech No. [2012] 035)

\subsubsection{Pursuing Rapid Growth on the Basis of a Reasonable Profit Margin}

Opportunities and market share are always the most important things for companies to consider when developing in a high-tech industry. But sometimes you have to sacrifice hefty profits to gain market share. (Ren Zhengfei: Speech at a Meeting with Financial Staff, 1997)

Our aim is to maximize growth while ensuring a certain profit margin. We need to maintain a growth rate that is higher than the industry average and our major competitors' growth rates, all to bring new life to the

\footnotetext{
${ }^{3}$ Liu Xiang: China's former Olympic 110-meter hurdles champion.
} 
company, attract the best people, and best allocate our operating resources. (Source: The Huawei Charter, 1998)

We need to maintain a growth rate that is higher than the industry average and our major competitors' growth rates. Over the years, our annual growth rate has remained at $100 \%$. In the future, our growth rate will inevitably slow as the baseline for further development goes up. It will be a huge challenge for us to find the right pace to maintain a relatively solid position in the industry. (Ren Zhengfei: How Long Can Huawei Survive?, 1998)

Rather than seeking maximum profits, we will set profitability targets that are sufficiently high, but reasonably tailored to different stages of development, to address our need for sustainable growth. (Source: The Huawei Charter, 1998)

Maximizing profits for us often means squeezing the profits of our customers and partners. Why should they tolerate this? (Ren Zhengfei: Managers Should Live and Pass on Huawei's Core Values - Speech at the First Workshop on Human Resource Management Outline, Huawei Executive Office Speech No. [2010] 009)

We need to separate mature and emerging industries during our appraisals. The company can strategically subsidize newly emerging industries during their first three to five years, and those industries can repay the company later on after they have grown. We shouldn't use a mature industry to subsidize an immature one. This support should be provided by the company, not by a product line. (Ren Zhengfei: Speech at the EMT ST Meeting on April 29, 2010)

\subsection{Long-Term Versus Short-Term Interests}

\subsubsection{Short-Term Interests Ensure Survival}

As long as we have a clear long-term goal, we should seize opportunities the moment when the window of opportunity opens and make profits. This can help us ensure that our long-term strategic products can survive and thrive. (Ren Zhengfei: Speech at the Dedication Conference of the Wireless Network Product Line, Huawei Executive Office Speech No. [2008] 007)

We can see the value of our long-term strategy only when we actually survive. Without short-term success though, there will be no basis on which to consider our longer-term strategy. Without a strategic vision and 
a clear view of the future, our short-term efforts will be no different than what Chinese peasants did for thousands years: working day in and day out with no innovation or change. To achieve sustainable and profitable growth, we need to consider financial indicators in the short term; in the medium term, we need to look at capability improvement; in the long term, we need to focus on the industry landscape, business ecosystem robustness, and industry sustainability. Business success will always be a concern for our company throughout its lifecycle. Management is about weighing the present against the future and balancing the short term and the long term. If short-term interests are gained at the cost of long-term interests, or even worse, at the cost of the company's survival, then it's clear that management has not made the right trade-off. This type of decision is irresponsible. (Ren Zhengfei: Our Transformation Goals Are to Harvest More Crops and Increase Soil Fertility-Speech at the 2015 Huawei Market Conference, Huawei Executive Office Speech No. [2015] 016)

A basic rule of business is equivalent exchange. If we can promptly and accurately provide high-quality and cost-effective services to our customers, we will naturally receive reasonable rewards in return. Some of these rewards will be in the form of short-term business interests, some in the form of mid-to-long-term business interests, but ultimately, they must all be reflected in the company's financial results: revenue, profits, and cash flow. Any business activity that results in ongoing losses has deviated from or misinterpreted our core value of customer centricity. (Ren Zhengfei: Our Transformation Goals Are to Harvest More Crops and Increase Soil Fertility-Speech at the 2015 Huawei Market Conference, Huawei Executive Office Speech No. [2015] 016)

\subsubsection{Striking a Balance Between Long-Term and Short-Term Interests}

We must enable our employees to fully recognize the relationship between short-term and long-term interests, and the significance of long-term investment. We must avoid short-termism, because it essentially kills the goose that lays golden eggs. We entered the communications industry out of naivety, not realizing that our competitors were global leaders. In the company's early years, driven by a sense of urgency, we had invested heavily in R\&D, market expansion, and talent development every year, even though $95 \%$ of our employees didn't own their own apartments. Thanks to this huge pressure, we became a strongly 
united company. The spirit of remaining dedicated and prioritizing work over life was internalized by all Huawei employees. (Ren Zhengfei: Characteristics of Huawei's Development, 1996)

Huawei as a company is most concerned about its long-term interests and how to constantly hone its long-term competitive edge. However, our employees are most concerned about their short-term interests, because they do not know whether they will continue to work for Huawei in the future. To resolve this contradiction, we need to strike a balance between long-term and short-term interests. (Ren Zhengfei: How Long Can Huawei Survive?, 1998)

Our core strategy should be future-oriented, with a clear execution roadmap. When strategic investment is required, we need to assess the value the investments have for the company using a long-term roadmap. For non-strategic investment, we need to look at the roadmap for shortterm improvement and profitability. (Ren Zhengfei: Speech and Comments at the Carrier BG's 2013 Strategy Retreat, Huawei Executive Office Speech No. [2014] 016)

Question: How can we balance long- and short-term goals? It will take a long time to turn research and algorithms into commercial products. Sometimes, this will cause conflict. Ren Zhengfei: This is why China hasn't made significant contributions to humanity over the past 5000 years. Archimedes was not from China, and Arabic numerals were not invented by the Chinese. There have been many great civilizations to stand beside the Chinese. A Chinese mindset often seeks to solve problems, whereas a Western mindset often seeks to find logic. This is why the ancient Chinese classic, The Nine Chapters on the Mathematical Art, is different from Euclid's geometry. How can you strike a balance between long-term and short-term goals? First, you should remain dedicated despite what others say about you. As long as not everyone is saying bad things about you, and as long as you have an opportunity to work, then things will be fine. You might say, "It's okay if you don't give me a pay raise. As long as I have got enough to eat, I think that will be okay." But if you succeed in 10 or 20 years' time, you will be a great $\mathrm{PhD}$ or scientist. Then you will have everything. Second, our organization should be lenient to such people. If Ludwig van Beethoven came to us to seek a job right now, I think he would definitely not get one. He was a deaf musician. Recruit him? Are you kidding me? Just think about it. So our organization must be lenient to scientific researchers. I welcome more people with great aspirations, but our culture is not yet inclusive enough. (Ren Zhengfei: 
Speech at a Meeting with Employees of the Noab's Ark Laboratory, Huawei Executive Office Speech No. [2016] 083)

Enterprises that last follow different principles than those that don't to balance short-term and long-term interests. These principles stem from how they understand their purpose - to create value for customers. (Ren Zhengfei: Our Transformation Goals Are to Harvest More Crops and Increase Soil Fertility-Speech at the 2015 Huawei Market Conference, Huawei Executive Office Speech No. [2015] 016)

\subsection{Centralization Versus Decentralization}

\subsubsection{Development: Staying Focused, Involving Little Uncertainty, and Supporting Business Success}

We first need to think carefully about what we do and what we don't do. We need to center our thinking on a number of general principles. Take high-speed network chips as an example. If we don't use many, why are we making them on our own? If we don't have to make them on our own, we can choose to collaborate with others for the time being. We will then free up some resources and invest them in our core products. We have a broader product portfolio than Lucent, Nokia, Ericsson, and Cisco. With such a wide line, how many resources do we need to get us ahead of the pack on all our products? This is the most pressing issue we face right now. (Ren Zhengfei: Speech at the Work Report of the Product Line Management Office, 2000)

We should not be too idealistic when it comes to product development. If a product fails, just close the project and quickly reassign its people. We shouldn't always strive for unreachable goals. Heroes should not spend too much time chasing perfection. By the time we achieve perfection, we may not exist any longer. We cannot wait for perfection to come, and we don't have the ability to make it happen ourselves. So we have to close failed projects. This does not mean that a failed project has no heroes. People from failed projects are also assets, because their wrong turns have brought us valuable experience. We need to have people circulating more quickly around the company. (Ren Zhengfei: Focusing on the Core Business and Seizing Strategic Opportunities - Speech at the Product Investment Strategy Review Meeting, Huawei Executive Office Speech No. [2015] 123)

Objectively, R\&D employees have made great contributions to the company's development. They need to explore new technologies. More 
importantly, they need to be sensitive to and integrate customer needs. They must develop products and services that meet customer needs. The R\&D's goal is to shift from developing products to supporting business success. Customers don't need products, they need services and operations. To achieve business success, we need to turn products into operation and service enablers. We cannot simply aim to hit our KPIs. Instead, we need to consider actual user experiences on our networks. Our products must be competitive, and must support business success. (Ren Zhengfei: There Will Not Always Be Flowers Along the Road Abead-Speech at the HI Huawei Market Conference, Huawei Executive Office Speech No. [2016] 079)

Development is a project of special certainty, and should be wellplanned, with well-managed budgets and accounting. Its finances should be transparent, not only in terms of investment, but also in terms of process management and accounting. We should develop a stronger finance team in R\&D. We should gradually work towards effective management. The reason why development projects have special certainty is that you can reapply for budgets if you fail. (Ren Zhengfei: The Essence of IPD: From Opportunity to Commercial Success-Speech at an Awards Ceremony for IPD Whiz Kids and Outstanding XDTs, Huawei Executive Office Speech No. [2016] 084)

During this year's budgeting process, we won't earmark much money for product development, since it is a job of certainty and needs to focus on targets and efficiency. Our budgets must be primarily allocated for future growth and breakthroughs in uncharted territory. We must not randomly take an investment-intensive approach. We need to review this approach carefully. Research and innovation on uncertainties must also have boundaries and serve our core business. We need to limit research and innovation initiatives that don't serve our core business. (Ren Zhengfei: Speech at the EMT ST Meeting on January 25, 2016, Huawei Executive Office Speech No. [2016] 054)

To break down management barriers, we ask that Products \& Solutions not initiate projects for small products. If they do, front-end management will become increasingly complex. Maybe we can talk about developing small products again after our processes are integrated. We must not randomly create small products, and we must use budgeting to make changes. We must close small products that can be closed. We can only shrink and simplify things to overcome management barriers. The simpler things are, the easier it will be for us to break down barriers. It is acceptable if you 
make things complex again after barriers are removed, but right now we can't break down barriers because we have taken on too much. (Ren Zhengfei: Speech at the EMT ST Meeting on January 25, 2016, Huawei Executive Office Speech No. [2016] 054)

\subsubsection{Research and Explove Across a Wide Scope}

Huawei is a company that deals with engineering, not one of basic scientific research. So, why are we entering the field of basic scientific research? Because electronics and information technologies are developing too rapidly. We cannot just sit around and wait until scientists complete their research and release their scientific papers. If we only begin to do engineering experiments based on our understanding of current scientific papers, and then use the results of those experiments to guide our engineering work, the cycle will be too long. We should thus start experimenting with engineering methods as soon as scientists raise questions during their basic research. This approach will enable us to respond to social development needs more rapidly and thus survive. Therefore, we need to enter the field of basic research in thermophysics. (Ren Zhengfei: Remarks at a Meeting at the National Academy of Sciences of Belarus, Huawei Executive Office Speech No. [2016] 087)

We should open our technology "bell mouth" wider to allow sufficient open cooperation and greater global collaboration. Our company has two strategies for the future: One is the customer strategy and the other is the technology strategy. Our technology "bell mouth" should be big enough to include all technologies, development paths, and directions - even less advanced technologies. They might lag behind for the time being, but this will not last forever. They will likely become more advanced than other technologies in the future. We can invest consistently in the same direction in different locations. Previously, we had red teams and blue teams. ${ }^{4}$ Now we all belong to blue teams. Whoever wins will be our red team. We are open to collaboration. We sponsor scientists, but we don't seek to own their scientific papers or patents. Instead, we just want to be informed of their research and how they solve specific problems and then learn from their failures. If we just wait until they release their research results, the

${ }^{4}$ As part of its ongoing effort to identify potential weaknesses, Huawei employs a "Red Team and Blue Team" method of self-reflection. The Blue Team plays the role of a competitor, always challenging the Red Team and exposing its faults to help the Red Team improve. 
cycle will be too long. We should thus begin to consider engineering application during scientists' theoretical explorations. Our partners do not necessarily need to succeed. Lessons learned from failures are also a kind of success. Scientists can illuminate us - and others - like beacons. However, we don't seek to own these beacons or interfere in how their research results are applied. (Ren Zhengfei: Remarks at a Meeting at the National Academy of Sciences of Belarus, Huawei Executive Office Speech No. [2016] 087)

Huawei's innovation is now mainly centered on engineering sciences, such as engineering-related mathematics and physical algorithms. We haven't truly begun researching in basic theories. We are gradually reaching the limits defined in Shannon's Theorem and Moore's Law, but theories that can tackle issues concerning massive amounts of data traffic and low latency have not yet emerged. The road ahead is full of uncertainties, and we don't know exactly where we are heading. Major innovations are key for survival in uncharted territory. Without theoretical breakthroughs, technological breakthroughs, and a solid technological foundation, explosive innovation would be impossible. (Ren Zhengfei: Dedicated to China's Century-old Dream of Revitalizing Science and Technology, Huawei Executive Office Speech No. [2016] 067)

At Huawei, we should stay focused on our core business. At the same time, we should "absorb the energy of the universe over a cup of coffee" to keep our wheels rolling ahead. We should resolutely forge ahead into uncharted territory where we will have no conflicts of interests with others. We are expanding in a fair and equitable manner. "Borrowing" energy from others is conducive to the development of the world as a whole. Large companies will not go against us. And smaller ones will be unable to keep up with us, so it would be pointless for them to talk against us. We can only fly freely once we get to uncharted territory, because we won't have competitors there. How do we define uncharted territory? First, there must be no one to tell us which path to take or which direction to go. Second, there must be no rules there, so we won't know where the traps might be. This is a completely new territory. Huawei used to follow others, and thus saved a great deal of money which should have been used for exploration. Today, we have to blaze a trail ourselves. Inevitably, we will make mistakes. (Ren Zhengfei: Remarks at Meetings with Huawei Fellows, Huawei Executive Office Speech No. [2016] 069)

We must not randomly use the word "failure" in the future. Instead, we should use "exploration", because heroes arise from both successes and 
failures. In any closed project, you should analyze its reasons for success or failure. Even if it fails, it was an exploration. (Ren Zhengfei: Remarks at Meetings with Huawei Fellows, Huawei Executive Office Speech No. [2016] 069)

Therefore, we should adjust how we view success and failure, as failure is also a treasure for us. We can also learn from failure, and it is the most precious learning experiences. How many times can we fail in our lives? We cannot repeat anything. We will retain dedicated employees from failed projects, so that they will not fail again in the future. Our HR team should reconsider this issue. Our appraisal system must not be rigid, and we should adopt flexible appraisal methods. (Ren Zhengfei: Remarks at Meetings with Huawei Fellows, Huawei Executive Office Speech No. [2016] 069)

We should embrace challenges and disruptions. We should not be afraid of disruptions. When real challenges emerge, we should meet them head on. Society is going to change. Dedication without a direction or sufficient strength would be meaningless. Small companies are not strong. Some big companies are strong, but have no direction. Huawei is a strong company, and is exploring its future direction. Why wouldn't we lead the future? (Ren Zhengfei: Remarks at Meetings with Huawei Fellows, Huawei Executive Office Speech No. [2016] 069)

The "Van Fleet Load" type of heavy investment along multiple paths and in multiple waves mainly focuses on research and innovation. The "bell mouth" at the upper end of our "de Laval nozzle" must be made wider. Our proportion of annual revenue invested in R\&D and our investment in management improvement are among the highest in the industry. In the past, we invested $20 \%$ of our R\&D budgets directly in research. We now plan to increase that to a higher ratio, say, $30 \%$ or a percentage that is reasonable; we need to do this step by step. Of course, the proportion of annual revenue invested in R\&D should also increase. (Ren Zhengfei: Scale New Heights and Forge Ahead into Uncharted Territory Along Multiple Paths in Multiple Waves-Key Messages of Discussions at Mobile World Congress and in Ukraine, Huawei Executive Office Speech No. [2016] 068)

In the future, our "Van Fleet Load" type of heavy investment will not be made in product development. We should not try to develop small products. Any such attempt will be strictly controlled. There has to be discipline in how we spend money in product development. Product development is part of delivery and a task of certainty. Planning, budgeting, accounting, and delivery management processes must be put in place. 
(Ren Zhengfei: Scale New Heights and Forge Ahead into Uncharted Territory Along Multiple Paths in Multiple Waves-Key Messages of Discussions at Mobile World Congress and in Ukraine, Huawei Executive Office Speech No. [2016] 068)

We can spend more on research and innovation. Our "Van Fleet Load" type of heavy investment should be used for future endeavors, but our exploration must have boundaries. We won't bring people outside these boundaries into our company, but I would welcome exceptional scientists who are willing to perform research within our scope of focus. They don't have to become Huawei staff; collaboration is also welcome. This way we can bring on board scientists from all over the world. But they don't have to join Huawei. As Ken $\mathrm{Hu}^{5}$ said, we need to weaken our "staff badge culture" over time. As long as scientists or talented people who may seem eccentric move in the same direction as us, we should sponsor them and create the future together. We should be more open-minded and share what we have achieved. For the upward facing "bell mouth" of the "de Laval nozzle", we will bring in a large number of like-minded partners to allow multiple paths for our research and innovation. With the "bell mouth" facing downward, we will communicate our core values to future generations and inspire them to join us. Development is a special project of certainty, and it should be well-planned, with well-managed budgets and accounting. If people doing development work make mistakes, they can reapply for budgets. (Ren Zhengfei: Scale New Heights and Forge Ahead into Uncharted Territory Along Multiple Paths in Multiple WavesKey Messages of Discussions at Mobile World Congress and in Ukraine, Huawei Executive Office Speech No. [2016] 068)

We should change the R\&D budget mix to increase our percentage of investment in research and innovation. We need to change the way we distribute our capabilities. Everything used to be stacked in Shenzhen, but in the future our centers of expertise will all be located wherever we can find the right resources. Some high-end, high-precision, and cutting-edge components can be manufactured in Germany or Japan, and then shipped to China. At the workshop to be held in Japan at the end of March, we can add a topic: Japanese craftsmanship. We can invite Japanese scientists to talk about the characteristics of Japanese craftsmanship, and we will pay them consulting fees. (Ren Zhengfei: Scale New Heights and Forge Ahead into Uncharted Territory Along Multiple Paths in Multiple Waves-Key

\footnotetext{
${ }^{5}$ Ken Hu: Rotating Chairman of Huawei.
} 
Messages of Discussions at Mobile World Congress and in Ukraine, Huawei Executive Office Speech No. [2016] 068)

We are willing to set up a Thought Research Center at the top of our organization. Our senior experts and senior managers can have brainstorming sessions at this research center and explore what direction the world may be heading. Our 2012 Laboratories can verify our ideas. We must be open-minded to embrace the world. The Thought Research Center should have a boundary, within which we will allow innovation by either our own staff or scientists outside Huawei. This will ensure that, if black swans appear, they will fly out of our coffee cups. We will be able to turn them into white swans. You are asking about a possible change in our organizational structure. We are now thinking about this change. (Ren Zhengfei: Minutes of a Meeting with Employees of the Japan Representative Office and the Japan Research Center, Huawei Executive Office Speech No. [2016] 080)

\subsubsection{Narrowing Our Strategic Focus and Setting Ourselves Apart from Competitors in Our Core Business}

When making major investment decisions, we don't necessarily have to pursue today's highly profitable projects. We also should pay attention to emerging markets with huge potential and growth opportunities in new products. We will not diversify our operations, as doing so would distract company resources and the energy of our top management away from what's important. (Source: The Huawei Charter, 1998)

To become a leader, we must narrow our strategic focus. We must focus our energy on our core business and strategic markets to seize the strategic high ground. Today I talked about bandwidth and an operating system for networks. If we can overtake all other players, we will very likely hold the future in our hands. (Ren Zhengfei: Speech and Comments at the Carrier Network BG's Strategy Retreat in Huizhou, Huawei Executive Office Speech No. [2012] 010)

We must focus on valued customers and valued regions. We must technologically integrate our R\&D, the macro pipe, the micro pipe, and the tap along our pipe strategy. Businesses that are not included in the above list should be generating large profits to support the company's strategy. The company should not scatter its investments just to realize scientists' dreams. Rather, scientists should dedicate themselves to the company's strategy. (Ren Zhengfei: Focusing on Strategy and Streamlining Management, Huawei Executive Office Speech No. [2012] 041) 
We think that broadband will be front and center in the future. As we move toward ultra-broadband, Huawei has the advantage to stay ahead of all other companies. Within the next three to five years, Huawei will have the capacity to seize this market segment. Information that flows through big data pipes will then flow to thinner pipes - enterprise networks. This will allow us to extend data flows to enterprises. We compare devices to water taps, through which data flows run. (Ren Zhengfei: Comments at a Meeting with Sales Financing Experts, Huawei Executive Office Speech No. [2012] 025)

As per our needle-tip strategy, we have entered uncharted territory where we have no competitors, won't step on the feet of others, and can improve the business ecosystem. This will give us greater bargaining power in product pricing. Haven't you noticed this effect during the last couple of years? Our products have been selling well, while still yielding higher profits. (Ren Zhengfei: Speech at a Meeting with Trainees at the First Training Session for the Sales Project Management Resource Pool, Huawei Executive Office Speech No. [2014] 066)

\subsection{Opportunities Versus Risks}

\subsubsection{Managing Both Opportunities and Risks, with More Attention Paid to Risks}

We need to look at risks from a value management perspective. Internal potential risks can be divided into three categories: First are implicit risks that have existed throughout our 20-plus years of rapid growth. Such risks may begin to surface when the external economic environment deteriorates or business growth slows down. These risks include long overdue accounts receivable, loss-bearing contracts, high-risk contracts, overcommitment, and unapproved vouchers in the hands of customers. We need to quantify, measure, and handle these risks, and gradually eliminate them. Second are the risks that arise from a slowdown of business growth. Huawei used to be a fast growing company. As long as revenue grew, profits grew as well. Our value assessment and distribution systems were also designed using a model founded on rapid growth. In 2011, the company's financial performance made this model ineffective. We saw revenue growth but profits declined sharply, and our growth rate was lower than that of our major competitors. A decline in growth could also cause a decline in our profitability and financial performance. This means we need to take operating efficiency very seriously, and guard against problems associated 
with contract quality, new business models, and special transaction models. We need to clarify issues surrounding authorization and approval, and ask boastful management teams to generate more profits. At the same time, we need to establish a mechanism that links budgeting and accounting to headcount, using value distribution to guide resource allocation and improve efficiency. The third category is risks that arise from uncertainty in investing in multi-core businesses. When developing our consumer and enterprise businesses, we must pay attention to the ratio, structure, and pace of our investments in people, capital, and materials. We need to ensure our investments are in line with the company's resource and business strategies. We should also pay special attention to a series of new problems with the Consumer BG's inventory and product quality as well as with the Enterprise BG's channel partners. And we need to develop solutions and capabilities to address these problems. (Guo Ping: Effectively Managing Corporate Value to Pursue Sustainable and Profitable Growth, Huawei Executive Office Speech No. [2012] 005)

The financial crisis is not over yet. Perhaps it hasn't even truly started yet, and we just can't predict its full impact yet. Huawei faces many challenges connected to the financial crisis. To evade the crisis and prevent our company's collapse, we must comply with the laws of the countries in which we operate, and follow established international practices. At present, we are strengthening our sales revenue management, and have developed accounting principles specifically for sales revenue. Our goal is to prevent any kind of "bubble effect" that will drive us into the financial crisis. We stand firm in our fight against accounting fraud, and will severely penalize anyone involved in it. (Ren Zhengfei: Speech at the Work Briefing of the West European Region, Huawei Executive Office Speech No. [2014] 073)

We are facing both opportunities and risks, and we should give greater weight to risks than sales. We should reduce expenses in countries where we cannot see opportunities and transfer employees there to our strategic reserves. (Ren Zhengfei: There Will Not Always Be Flowers Along the Road Ahead-Speech at the HI Huawei Market Conference, Huawei Executive Office Speech No. [2016] 079)

\subsubsection{Inaction Has No Risk, But Will Leave Us Bebind}

Of course, if we do nothing, we will face no risks. But we will definitely be overtaken. In the future, we are likely to attract more attention as we 
become stronger. If we want to do something great, we must manage our compliance risks more effectively. Wherever risks and challenges are discovered, we must be honest about them. No cover-ups, no hiding. (Ren Zhengfei: Remarks During Visits to Countries Where Cash Is Trapped, Huawei Executive Office Speech No. [2015] 023)

We have spent 25 years building high-quality platforms and have managed to gather resources. These resources are valuable assets that came after much money was wasted by our senior managers and experts. Failed projects and products wasted money. Of course the money wasted was money you earned in the first place. We would not be where we are today without such waste. We value the success that we have achieved by learning from our failures. So long as we refuse to be complacent, boldly walk away from what we have, and have the courage to embrace new things, Huawei may not necessarily fall behind. (Ren Zhengfei: Applying the Spirit of the Tortoise to Catch up with the Dragon Spacecraft-Speech at Huawei Annual Management Conference 2013, Huawei Executive Office Speech No. [2013] 255)

\subsubsection{Promoting Sales Growth While Effectively Managing Risks}

We must assess risks based on facts. Just as the Yangtze River needs to keep flowing, we must not discontinue our business flows just to play it safe. (Source: Minutes of the Work Report on Risk Management, EMT Meeting Minutes No. [2005] 059)

The company's goal is to promote sales growth while effectively managing risks. During contract terms reviews, some functional departments simply say "No" without proposing any feasible solutions. They do this because these departments don't have to meet sales targets. We must establish a management mechanism that changes this lack of alignment between responsibility and authority. (Source: Minutes of the Report on the 2009 HI Performance Review, EMT Meeting Minutes No. [2009] 038)

We must be fully aware that, in the face of the risks ahead, we can only use the certainty of rules to deal with the uncertainty of results. This is how we can follow our heart without breaking rules and gain greater freedom through development. There are two sides to every coin. Huidu in our management allows us to survive and thrive. We must thoroughly understand openness, compromise, and buidu, and the company's philosophy of "Digging In and Widening Out". The light of wisdom will 
never fade away. (Ren Zhengfei: Digging In, Widening Out-Speech at the Commendation Meeting of the Operations and Delivery Division, Huawei Executive Office Speech No. [2009] 009)

Representative offices need to agree with BGs on their annual business goals, and be responsible for attaining these goals. Low-profit and highrisk projects should be subsidized by BGs. If they aren't, then representative offices need to have the authority to veto such projects. However, when exercising veto authority, representative offices should also be responsible in part for BGs' business goals, and avoid sacrificing growth opportunities as a result of an excessive focus on profits and risks. (Source: Resolution on Piloting Organizational Design and Authorization Management Principles in the Guangzhou Representative Office, EMT Resolution No. [2012] 033)

We should pay more attention to risks when managing our opportunities and risks. This means that we should have a rational strategic presence. It is not that risks are greater than opportunities in all the countries where we operate. We divide these countries into two categories. One is countries where risks are being controlled, and where managing risks is more important than managing opportunities. The other is countries where risks are not a major focus. In these countries, we need to be opportunitydriven and strive to identify and seize opportunities. (Ren Zhengfei: Minutes of the Report on the Opportunity to Order for 2017, EMT Meeting Minutes No. [2016] 021)

The purpose of managing risks is to help create value, effectively balance business expansion and risk control, and avoid leaning towards either extreme of ignoring risks or being excessively conservative. Representative offices should be profit-centered and must ensure they always comply with trade rules and regulations. When striking a balance between expansion and control, business commanders might approach or even cross the red line. When this happens, subsidiary board directors must ensure business compliance, but they are not there to control business. Instead, they need to charge forward along with business commanders, and help them succeed and achieve internal and external compliance during the journey. The responsibility of business commanders is to succeed and the responsibility of subsidiary board directors is to ensure compliance while helping achieve success. Although these responsibilities are different, they have the same goal, which is to succeed, rather than to exercise strict control or micromanage people like they are toddlers. If no crops are harvested, what's the point of implementing management and control? (Ren Zhengfei: Speech at 
the Meeting on Extension of the Company's Oversight and Management Control System, Huawei Executive Office Speech No. [2017] 041)

\subsection{Creating Order Out of Chaos Versus Creating Chaos Out of Order}

\subsubsection{Purpose of Fine-Grained Management: Preventing Chas During Business Expansion}

Willingness to improve management is not enough. We also need to improve how the company approaches management. Otherwise, we will never be efficient and will eventually meet our demise. The per-capita efficiency of Huawei is at least three times lower than that of our Western peers. So what is being wasted? Resources and time. This is a result of ineffective management. (Ren Zhengfei: Do Not Be a Temporary Hero, 1998)

Fine-grained management represents planning, budgeting, and accounting, all of which need to be based on reliable data. Representative offices manage their operations based on plans and financial data. Only when financial data is clear will financial analysis be clear. Clear financial analysis is the basis for setting clear management KPIs. These, in turn, will tell us what areas need to improve and how, guide future business development, and help develop reasonable and feasible business strategies and action plans. How can we achieve fine-grained management? The key is to have a reasonable plan and avoid being blind. Planning is critical because it is the basis for budgeting. Plans and budgets can then be corrected and measured through accounting. Fine-grained management, as I mentioned, is not about pursuing a low cost strategy; instead, it is about how to make more contributions to the company with the same budget. These two strategies are different. Fine-grained management is an open strategy while pursuing a low cost strategy is a closed one. (Ren Zhengfei: Speech at the Report by the BT Account Department and the UK Representative Office, Huawei Executive Office Speech No. [2007] 015)

Representative offices need to use financial data to guide people to specify and clarify business strategies and measures, and use report templates to implement fine-grained management. These goals are particularly critical during planning, budgeting, and accounting. Fine-grained management that focuses on planning and operations is the core basis of profit-centered performance appraisals, and is also the direction of the company's business center development. Fine-grained management is a 
prerequisite for implementing profit-centered performance appraisals and ensuring accurate and reliable profit data. (Ren Zhengfei: Speech at the Report by the BT Account Department and the UK Representative Office, Huawei Executive Office Speech No. [2007] 015)

For fast-growing markets and products, our main objective is to win strategic projects, more customers, and more market share. At the same time, we should carry out fine-grained management to prevent chaos caused by blind expansion. When appraising growth, we need to look at sales revenue, sales growth potential, and breakthroughs with tier-1 carriers. When I say we should win more customers, I do not only mean geographically, but also from product and carrier perspectives. Doing that is like shaping the market landscape. When it comes to mature markets where we are growing steadily but have limited potential for growth and to products in the final stage of their lifecycles, we need to focus on finegrained management while exploring new opportunities. We have clear appraisal criteria for such markets and products: generating cash flow and profits for the company. (Source: Guidelines on Sales Priorities, EMT Meeting Minutes No. [2008] 014)

We don't focus too much on growth. Regions that are growing slowly now might have been growing rapidly a couple years earlier. In such regions, we want to focus on effective, fine-grained management. Eventually, the managers and management approaches of these regions should be transferred to expansion teams. All departments will at some point struggle with further expansion and will need to implement finegrained management. This doesn't mean teams that are still advancing don't need this type of management though. Therefore, I think that our planning system should be used to facilitate operations, not to report to HQ. You must keep this in mind. If you ignore this, our company will gradually shrink. (Ren Zhengfei: Remarks After Watching the Battle of Moscow-Speech at the Egypt Representative Office, Huawei Executive Office Speech No. [2008] 004)

Our profits now come from growth rather than management. With this model, if the company stops growing, we will have negative profits and cash flows. So we need to increase internal efficiency before we stop growing. (Ren Zhengfei: Speech at the EMT ST Meeting in May, 2009)

When we were growing rapidly, we focused too much on sales. This was because more contracts meant more profits. As the market becomes saturated, there are fewer and fewer opportunities for us to seize and make profits on. To survive, we need to implement fine-grained management. 
(Ren Zhengfei: Remarks at a Meeting with Senior Managers at a Project Management Summit, Huawei Executive Office Speech No. [2009] 007)

Huawei is a company that has developed out of chaos. If we didn't use processes or appraisals to drive high performance, we will be slaves to Brownian motion, where each molecule acts on its own and momentum for growth cannot be achieved. After standardization, everything works well according to processes, just like gas flows through the "de Laval nozzle". When compressed gas reaches the velocity of sound, it continuously expands, creating an extremely fast jet engine. This is how rockets work. Rocket engines are based on the "de Laval nozzle". We at Huawei have followed a path of "standardization first, and then less control". (Ren Zhengfei: Remarks at Meetings with Huawei Fellows, Huawei Executive Office Speech No. [2016] 069)

\subsubsection{Striking and Disrupting a Balance}

When I last spoke at our UK Representative Office, I emphasized finegrained management. By that, I meant we must create order out of chaos. What I didn't mention was the need to seek to create chaos out of order, or to disrupt balance to expand further. During actual work, some representative offices are deviating from what I said. During my recent visit to the Mexico Representative Office, I said that doing business is not like painting or embroidery, and we need more than just fine-grained management. We must have clear goals, and focus on the most important issue in the market and the key factors that influence the issue. If we only emphasize fine-grained management, we will shrink. The purpose of fine-grained management is to prevent chaos during expansion, not to seal our doors closed. Fine-grained management doesn't mean we stop expanding. We must stand up to face the competition, and we must have the courage to win. This is necessary to become skilled at achieving success. Fine-grained management doesn't conflict with expansion, so we just have to effectively combine them. (Ren Zhengfei: Speech at the UK Representative Office, Huawei Executive Office Speech No. [2007] 027)

We need to change from one-size-fits-all management approaches to more scenario-specific approaches. These appraisals should guide the balanced development of our company. Over the years, we have moved away from chaos and gradually standardized our operations. We have made significant advancements in our management systems and established a large platform. This is a great accomplishment. I think that our overall HR 
policy of first establishing a large platform is correct. However, our performance appraisal approach is too rigid. The next time we transform our incentive systems, we should continue to emphasize different incentive models for different products, regions, and types of work. (Ren Zhengfei: Speech at the 2008 Mid-year Report by Regions to the EMT, EMT Meeting Minutes No. [2008] 028)

There is an old Chinese saying to the effect that the Yellow River changes course every 30 years. Huawei has survived for nearly 30 years, and is thus approaching an age when many companies falter and fail. To continue to survive, we must change everything from our organizational structure to our talent management approaches. If we don't change, we will not be able to survive. If we discard this generation of our existing employees and replace it with a completely new generation, there will be discontinuity. History proves that this approach is not feasible. Thus, what we can do is to reinvent our experienced employees. Through change, we will inject new energy into our existing workforce. This generation of employees can bridge the past and the future, and grow by inheriting knowledge and experience from the previous generation. (Ren Zhengfei: Speech at a Briefing on Strategic Reserve Development, Huawei Executive Office Speech No. [2016] 085)

We must not confine ourselves to our own circles, and must be openminded. In the field of machine learning, there must be a lot of software that is far better than ours out there. There must be many people who will launch amazing things. We need to cooperate with the best companies in this field. As we build our own Great Wall, we should use American bricks here, European bricks there, and also Japanese bricks. It doesn't matter where the bricks come from. We will use them as long as they help us win. We don't need to make every brick ourselves. On this big platform or "stage", our own Great Wall, we allow all sorts of people to give great performances like Riverdance. We will also allow the eccentric to dance on our "stage". They will not overwhelm the platform; instead, they will revitalize it. We will focus on our core business and at the same time leverage other people's advantages. This is what I just said about GTS, and our efforts in AI should focus on the several areas I just mentioned. (Ren Zhengfei: Speech at a Meeting with Employees of the Noah's Ark Laboratory, Huawei Executive Office Speech No. [2016] 083)

We are now in an age of innovation. After much of our work with certainty and uncertainty are integrated into processes, the emergence of new things will be inhibited. Japan is a great country, as it standardizes every- 
thing, even the simplest things, including how screwdrivers, components, and tissue paper are stored in workshops. Young workers have to strictly follow these standards, and as a result, they don't want to create new things. The UK is also a great country. One of its most notable cultural products that it exports is its system of rules. The UK has rules for every part of a process, even at the end. In contrast, the US is a country set up by all sorts of European immigrants. They tore apart the UK's system, and instead only standardized their overall legal framework. They didn't overstandardize the details. In this way, the US reshaped British culture, creating a prosperous country within only 200 years. (Ren Zhengfei: Remarks at Meetings with Huawei Fellows, Huawei Executive Office Speech No. [2016] 069)

Open Access This chapter is licensed under the terms of the Creative Commons Attribution-NonCommercial-NoDerivatives 4.0 International License (http:// creativecommons.org/licenses/by-nc-nd/4.0/), which permits any noncommercial use, sharing, distribution and reproduction in any medium or format, as long as you give appropriate credit to the original author(s) and the source, provide a link to the Creative Commons licence and indicate if you modified the licensed material. You do not have permission under this license to share adapted material derived from this chapter or parts of it.

The images or other third party material in this chapter are included in the chapter's Creative Commons licence, unless indicated otherwise in a credit line to the material. If material is not included in the chapter's Creative Commons licence and your intended use is not permitted by statutory regulation or exceeds the permitted use, you will need to obtain permission directly from the copyright holder. 